\title{
Golgi localization and dynamics of hyaluronan binding protein 1 (HABP1/ p32/C1QBP) during the cell cycle
}

\author{
Aniruddha SENGUPTA ${ }^{1}$, Bhaswati BANERJEE ${ }^{1}$, Rakesh K. TYAGI ${ }^{2}$, Kasturi DATTA ${ }^{1,2, *}$ \\ ${ }^{1}$ Biochemistry Laboratory, School of Environmental Sciences, Jawaharlal Nehru University, New Delhi-110067, India \\ ${ }^{2}$ Special Centre for Molecular Medicine, Jawaharlal Nehru University, New Delhi, India
}

\begin{abstract}
Hyaluronan binding protein 1 (HABP1) is a negatively charged multifunctional mammalian protein with a unique structural fold. Despite the fact that HABP1 possesses mitochondrial localization signal, it has also been localized to other cellular compartments. Using indirect immunofluorescence, we examined the sub-cellular localization of HABP1 and its dynamics during mitosis. We wanted to determine whether it distributes in any distinctive manner after mitotic nuclear envelope disassembly or is dispersed randomly throughout the cell. Our results reveal the golgi localization of HABP1 and demonstrate its complete dispersion throughout the cell during mitosis. This distinctive distribution pattern of HABP1 during mitosis resembles its ligand hyaluronan, suggesting that in concert with each other the two molecules play critical roles in this dynamic process.
\end{abstract}

Keywords: Hyaluronan Binding Protein 1 (HABP1), hyaluronan, sub-cellular localization, golgi, mitosis.

\section{INTRODUCTION}

Hyaladherins, a family of proteins interacting with hyaluronan (HA) [1], have long been attributed to numerous cellular functions. One such hyaladherin, implicated in cellular functions like adhesion and tumor invasion [2], sperm maturity and motility [3] and cellular signalling [4] is the Hyaluronan Binding Protein 1 (HABP1), which is represented as synonyms of $\mathrm{p} 32 / \mathrm{C} 1 \mathrm{QBP}$ in human chromosome 17p12-13 (accession number NP 001203). It is a sialic acid containing glycoprotein being synthesized as a pro-protein of 282 amino acids, from which the first 73 amino acids are proteolytically cleaved off to generate the mature protein of 209 amino acids [5]. This protein is homologous to a splicing factor associated protein p32 [5]. Utilizing approaches such as cell fractionation and immunostaining, HABP1 has been localized not only to cell-surface [6], but also to different subcellular compartments like mitochondria [7] and the nucleus [8]. Though, only a mitochondrial localization signal is well characterized in the precursor form [7], studies with the tagged mature protein revealed that it pre-

\footnotetext{
*Correspondence: Kasturi DATTA

Tel: +91-11-26172438 or 26704327; Fax: +91-11-26717502;

E-mail: kdatta@mail.jnu.ac.in
}

dominantly localizes in the nucleus [9]. The ability of HABP1 to interact with diverse range of proteins, coupled with its multiple intracellular localization, led to the proposition that HABP1 could be involved in cellular trafficking pathway(s) connecting the nucleus, mitochondria and cytoplasm and the export pathway to the cell surface [9]. A recent study from our laboratory has also shown that transient expression of HABP1 in mammalian cells alters their morphology and induces cytoplasmic vacuoles formation [10]. This study also highlighted that the orchestration of 'HA pool' by hyaladherins might play a key role in regulating the cellular functions of HA, as HA has long been known to play a pivotal role in multiple cellular functions $[11,12]$. Studies have shown that HA-dependent pericellular matrix formation is a rapid process, occurring specifically as cells de-adhere during mitotic cell rounding and during locomotion, indicating its involvement in regulating de-adhesion of cells from the substratum [12]. In addition to its presence in the extracellular matrix, growing evidence indicate that HA is also present in the cytoplasm and nuclei of cells in a number of tissues $[13,14]$. Intracellular HA has been speculated to be involved in nucleolar function, chromosomal rearrangement or other events in proliferating cells [15].

In light of the above-mentioned cellular functions of HABP1 and HA, we extrapolate the sub-cellular localiza- 
tion of endogenous HABP1 to the golgi network, substantiating its glycoprotein nature. We also report its dynamic behaviour in asynchronous cultured cells undergoing natural mitotic process, which resembles that of its ligand HA.

\section{MATERIALS AND METHODS \\ Cell culture}

The origin-defective SV40-transformed green monkey kidney cells (COS-1), obtained from National Center for Cell Science (Pune, India) were grown in Dulbecco's modified Eagle's medium (DMEM) supplemented with $10 \%$ heat-inactivated fetal calf serum, $100 \mu \mathrm{g} /$ $\mathrm{ml}$ penicillin and $100 \mu \mathrm{g} / \mathrm{ml}$ streptomycin (Invitrogen). For reasons of simplicity, the DMEM supplemented with all the above components will henceforth be referred to as 'complete medium'. The cultures were maintained in a $\mathrm{CO}_{2}$ incubator at $37^{\circ} \mathrm{C}$ in a humidified environment containing $5 \% \mathrm{CO}_{2}$.

\section{Immunofluorescence studies for sub-cellular localization of HABP1}

Asynchronous cultures of COS-1 cells, grown on glass cover slips were fixed in $-20^{\circ} \mathrm{C}$ methanol for $15 \mathrm{~min}$, air-dried and consequently equilibrated in PBS (pH-7.4). Methanol fixation was performed as it provides a single step fixation and does not appear to induce artifacts when working with fluorescent probes and tags [16]. The cover slips were pre-incubated in 1\% BSA-PBS, followed by incubation with rabbit anti-HABP1 antibody (1:100 dilutions in 1\% BSA-PBS) for $2 \mathrm{~h}$ at room temperature. The cover slips were washed thrice with PBS and incubated for $1 \mathrm{~h}$ with Cy-3-conjugated secondary antibody (sheep anti-rabbit IgG, Sigma, 1:250 dilutions in 1\% BSAPBS). The cells were washed thrice with PBS and mounted in PBS/ glycerol. Controls were carried out with an identical procedure, except that the primary antibody was replaced with a pre-immune serum.

\section{Detection of Golgi}
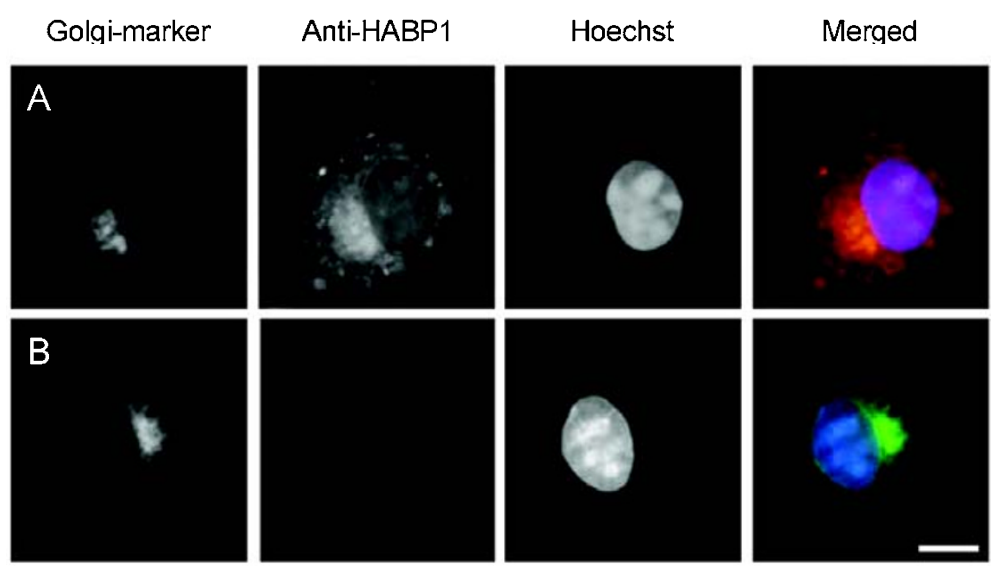

Fig. 1 The localization of endogenous HABP1 in the golgi of COS-1 cells. Asynchronous cultures of COS-1 cells, grown on glass cover slips were used for the sub-cellular detection of endogenous HABP1. The image shows results for (A) anti-HABP1 antibody and (B) pre-immune serum, with the field illuminated for BODIPY $\mathrm{FL} \mathrm{C}_{5}$-ceramide (Column 1), Cy-3 fluorescence (Column 2), Hoechst fluorescence (Column 3) and a superposition of the three images (Column 4). The bar represents $10 \mu \mathrm{m}$. 

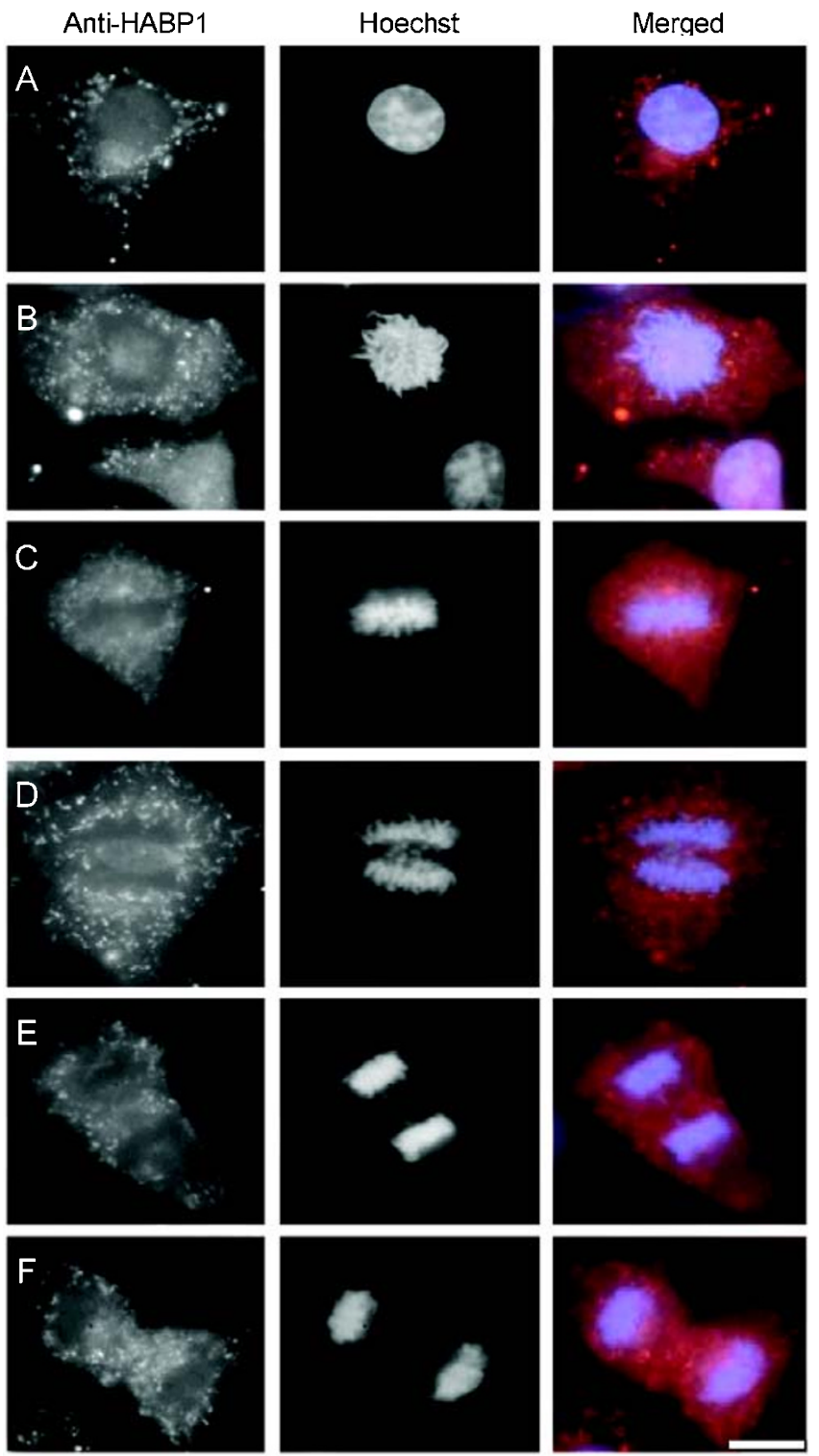

Fig. 2 Distribution of endogenous HABP1 during different mitotic stages of COS-1 cells by indirect immunofluorescence. Asynchronous cultures of COS-1 cells, undergoing natural mitosis were processed and immunodetected for endogenous HABP1, as described in Fig. 1. Each row of photograph contains the same field illuminated for Cy-3 fluorescence (Column 1), Hoechst fluorescence (Column 2), and a superposition of the two images (Column 3). The figure shows (A) interphase; (B) prophase; (C) metaphase; (D) anaphase; (E) telophase; (F) two separating cells. The bar represents $15 \mu \mathrm{m}$.

cation of its glycoprotein nature needs to be elucidated. To obtain an insight into the cellular functions of HABP1, we made an attempt to explore its dynamics in asynchronously growing COS-1 cells undergoing natural mitosis. The distribution profile of HABP1 during different mi- totic stages of COS- 1 cells was corroborated with Hoechst staining of the DNA (Fig. 2, Column 1, 2). The images are presented in mitotic order, with a cell in interphase at the top, two separating cells at the bottom, and the intermediate stages between the two. During interphase, HABP1 localizes in the nucleus and the golgi-network with interspersed dots in the cytoplasm representing mitochondria (Fig. 2A). The cells containing condensed chromatin, a characteristics of prophase, showed HABP1 being dispersed throughout the cell. This perception is reinforced when the two images are overlaid (Fig. 2B). Later, in metaphase (Fig. 2C), HABP1 disperses throughout the cell but is virtually excluded from the metaphase plate. Along anaphase, telophase and separating daughter cells, HABP1 staining was strong and appeared to be diffused throughout the cell, extending into the space between separating chromosomes but continued to be excluded from the volume occupied by DNA (Fig. 2D, E, F).

The dispersion pattern of HABP1 during mitosis is similar to most proteins of golgi-membrane and nucleus [17, 18]. Most interestingly however, the distribution pattern and retention of HABP1 during different stages of mitosis resemble that of its primary ligand, HA [15]. Keeping in view the distribution profile of HA during mitosis, it has been previously postulated that HA may be involved in chromosome condensation, possibly through interactions with lamins [15]. The ability of HA to regulate cell-cell and cell-substrate adhesion [19] combined with its water retention property indicates its functional implication during mitosis. Though the similarity between distribution patterns of HA and HABP1 during mitosis has not yet been established, such co-distribution may regulate chromosomal organization, presumably through interactions with histones, lamins or lamin binding proteins. In this connection, it is especially important to recall that HABP1 has already been shown to interact with the lamin B receptor (LBR), a nuclear protein [20]. During interphase, LBR forms a complex with the participation of lamin A and $\mathrm{B}$, a specific LBR kinase and three other proteins, one of which was later identified as HABP1/p32 [21]. In this perspective, the interaction of HABP1 with LBR may also facilitate the process of chromosomal organization during mitosis. $\mathrm{Cdc} 37$ is a protein, which has been characterized as a hyaladherin in chicken and as an essential cell cycle regulatory protein in yeast and Drosophila [22]. The role of HABP1 in cell-adhesion is well established and in combination with HA, it might facilitate the process of adhesion and de-adhesion during mitotic stages. In brief, this study extends the sub-cellular localization of HABP1 to the golgi network and reveals its distribution pattern during mitosis. The pattern of distribution and retention of HABP1 during mitosis resembles that of its ligand HA, 
suggesting that in concert with each other the two molecules play critical roles in this dynamic process.

\section{ACKNOWLEDGMENTS}

This work was supported by grants from the Department of Biotechnology, Government of India. We acknowledge the University Grants Commission for research fellowship.

Received, June 29, 2004

Revised, Aug 29, 2005

Accepted, Jan 25, 2005

\section{REFERENCES}

1 Toole BP. Hyaluronan and its binding proteins, the hyaladherins. Curr Opin Cell Biol 1990; 2:839-44.

2 Gupta S, Datta K. Possible role of hyaluronectin on cell adhesion in rat histiocytoma. Exp Cell Res 1991; 195:386-94.

3 Ranganathan S, Ganguly A, Datta K. Evidence for presence of hyaluronan binding protein on spermatozoa and its possible involvement in sperm function. Mol Reprod Dev 1994; 38:69-76.

4 Rao CM, Deb TB, Datta K. Hyaluronic acid induced hyaluronic acid binding protein phosphorylation and inositol triphosphate formation in lymphocytes. Biochem Mol Biol Int 1996; 40:32737.

5 Deb TB, Datta K. Molecular cloning of human fibroblast hyaluronic acid-binding protein confirms its identity with $\mathrm{P}-32$, a protein co-purified with splicing factor SF2. Hyaluronic acid-binding protein as $\mathrm{P}-32$ protein, co-purified with splicing factor SF2. J Biol Chem 1996; 271:2206-12.

6 Gupta S, Babu BR, Datta K. Purification, partial characterization of rat kidney hyaluronic acid binding protein and its localization on the cell surface. Eur J Cell Biol 1991; 56:58-67.

7 Dedio J, Jahnen-Dechent W, Bachmann M, Mueller-Esterl W. The multiligand-binding protein $\mathrm{gC} 1 \mathrm{qR}$, putative $\mathrm{C} 1 \mathrm{q}$ receptor, is a mitochondrial protein. J Immunol 1998; 160:3534-42.

8 Matthews DA, Russell WC. Adenovirus core protein V interacts with p32-a protein which is associated with both the mitochondria and the nucleus. J Gen Virol 1998; 79:1677-85.

9 van Leeuwen HC, O'Hare P. Retargeting of the mitochondrial protein $\mathrm{p} 32 / \mathrm{gC} 1 \mathrm{qR}$ to a cytoplasmic compartment and the cell surface. J Cell Sci 2001; 114:2115-23.
10 Sengupta A, Tyagi RK, Datta K. Truncated variants of hyaluronan -binding protein 1 bind hyaluronan and induce identical morphological aberrations in COS-1 cells. Biochem J 2004; 380: 837-44.

11 Brecht M, Mayer U, Schlosser E, Prehm P. Increased hyaluronate synthesis is required for fibroblast detachment and mitosis. Biochem J 1986; 239:445-50.

12 Evanko SP, Angello JC, Wight TN. Formation of hyaluronan and versican rich pericellular matrix is required for proliferation and migration of vascular smooth muscle cells. Arterioscler Thromb Vasc Biol 1999; 19:1004-13.

13 Margolis RK, Crockett CP, Kiang WL, Margolis RU. Glycosaminoglycans and glycoproteins associated with rat brain nuclei. Biochim Biophys Acta 1976; 451:465-9.

14 Eggli PS, Graber W. Association of hyaluronan with rat vascular endothelial cells and smooth muscle cells. J Histochem Cytochem 1995; 43:689-97.

15 Evanko SP, Wight TN, Intracellular localization of hyaluronan in proliferating cells. J Histochem Cytochem 1999; 47:1331-42.

16 Tyagi RK, Lavrovsky Y, Ahn SC, et al. Dynamics of intracellular movement and nucleocytoplasmic recycling of the ligandactivated androgen receptor in living cells. Mol Endocrinol. 2000; 14:1162-74.

17 Zaal KJ, Smith CL, Polishchuk RS, et al. Golgi membranes are absorbed into and reemerge from the ER during mitosis. Cell 1999; 99:589-601.

18 Yang L, Guan T, Gerace L. Integral membrane proteins of the nuclear envelope are dispersed throughout the endoplasmic reticulum during mitosis. J Cell Biol 1997; 137:1199-210.

19 Lee GM, Johnstone B, Jacobson K, Caterson B. The dynamic structure of the pericellular matrix on living cells. J Cell Biol 1993; 123:1899-907.

20 Simos G, Georgatos SD. The lamin B receptor-associated protein p34 shares sequence homology and antigenic determinants with the splicing factor 2-associated protein p32. FEBS Lett 1994; 346:225-8.

21 Simos G, Georgatos SD. The inner nuclear membrane protein p58 associates in vivo with a 558 kinase and the nuclear lamins. EMBO J 1992; 11:4027-36.

22 Grammatikakis N, Grammatikakis A, Yoneda M, Yu Q, Banerjee $\mathrm{SD}$, Toole BP. A novel glycosaminoglycan-binding protein is the vertebrate homologue of the cell cycle control protein, Cdc37. J Biol Chem 1995; 270:16198-205. 